\title{
6. DIREITOS DOS DOENTES EM CONTEXTO DE PANDEMIA
}

André Dias Pereira, Ana Elisabete Ferreira e Carla Barbosa

\section{Introduçáo}

O surgimento e evoluir da pandemia trouxe desafios que no início de 2020 seriam inimagináveis. Como reação às necessidades que surgiram, as entidades governativas tiveram de lançar mão de instrumentos legalmente estabelecidos que permitiram a adoção de certas medidas. O estado de emergência previsto na Constituição da República Portuguesa só pode ser declarado nos casos de agressão efetiva ou iminente por forças estrangeiras, de grave ameaça ou perturbação da ordem constitucional democrática ou de calamidade pública. É esta última realidade que vivemos atualmente.

Contudo, o decretar do estado de emergência em caso algum pode afetar os direitos à vida, à integridade pessoal, à identidade pessoal, à capacidade civil e à cidadania, à não retroatividade da lei criminal, às garantias de defesa dos arguidos e à liberdade de consciência e de religiáo. Vejamos, no entanto, como a pandemia e as medidas adotadas afetaram os direitos dos doentes em contexto de pandemia.

\section{a) Coordenadas do Sistema de Saúde português}

Pode afirmar-se que Portugal tem um alto padrão de serviços de saúde. O sistema de saúde português ficou em $13 .^{\circ}$ lugar, em 2018, no Euro Health Consumer Index (EHCI), subindo sete posiçóes em relação a 2015 (e afastando-se definitivamente do 25. ${ }^{\circ}$ lugar, em que se encontrava em 2012), para ficar à frente do Reino Unido e da Espanha, pela primeira vez. Portugal teve um desempenho particularmente bom em 
classificaçôes de qualidade-preço. Já no World Health Report, organizado pela Organizaçáo Mundial de Saúde, publicado em 2020, relativo ao ano de 2019, encontra-se na 12 . $^{\text {a }}$ posiçãa ${ }^{1}$.

De acordo com os dados da Pordata de 2019, o nosso país gasta atualmente cerca de $9,5 \%$ do seu PIB em cuidados de saúde. De acordo com o European Observatory of Health Systems and Policies, 2019, embora tenha existido um aumento com as despesas em saúde quando feita a comparação com o período da crise económica, em 2017, Portugal gastou 2029 euros per capita em cuidados de saúde (9\% do PIB), que é cerca de um terço menos do que a média da UE (2 884 euros). Os pagamentos diretos tornaram-se a segunda maior fonte de receita, atingindo $27,5 \%$ das despesas totais com saúde. Como parte do reforço dos cuidados primários, o Governo assumiu como medidas necessárias o aumento de médicos de clínica geral para o Serviço Nacional de Saúde, o aumento de utentes com acesso a médicos de clínica geral e familiar (os vulgarmente designados médicos de família) e dar aos municípios um papel mais relevante e interventivo na gestão dos cuidados de saúde primários ${ }^{2}$.

No contexto do perfil de saúde, e de acordo com dados do Observatório da OCDE de 2019, Portugal demonstra eficácia no tratamento de patologias crónicas pelos cuidados primários e de ambulatório, com taxas de admissão evitáveis bastante abaixo da média europeia, e apresenta um alto desempenho no tratamento de certas doenças, como o cancro, registando taxas de sobrevivência acima dos restantes estados-membros.

As maiores fragilidades que lhe são apontadas não têm, contudo, sofrido alteraçóes importantes nos últimos cinco anos, mantendo uma infeliz continuidade: o nosso país precisa de diminuir as disparidades socioeconómicas e de género para alterar o perfil de saúde dos cidadãos; precisa de diminuir o impacto de fatores de risco como a obesidade e fatores comportamentais (como o consumo excessivo de álcool e de tabaco); demanda a diminuição das listas de espera para consulta e cirurgia programadas; e necessita de uma melhor e mais intensa alocação de recursos humanos.

1 Relatório completo e tabelas de estatísticas disponíveis em https://www.who. int/data/gho/publications/world-health-statistics

2 Relatório disponível em https:/ec.europa.eu/health/sites/health/files/state/ docs/2019_chp_pt_english.pdf 
Em 1976, a Constituição Portuguesa proclamou o direito dos cidadãos à proteção da saúde através da "criação de um Serviço Nacional de Saúde universal e gratuito" (art. 64. ${ }^{\circ}$ ) e, em 1979, a Lei n. $56 / 79$, de 15 de setembro, cria o Serviço Nacional de Saúde (SNS) como um sistema de saúde universal e geral, gratuito no ponto de uso.

Os ventos da abertura à economia de mercado e ao neoliberalismo chegaram a Portugal no final dos anos 80, afetando também o desenho da política de saúde. Assim, uma revisão da Constituição, em 1989, veio eliminar a total gratuitidade, ao admitir um SNS "tendencialmente gratuito" e a Lei de Bases da Saúde foi reformulada, em 1990, com maior abertura ao mercado privado de saúde. Ainda assim, a estrutura fundamental do sistema baseado na prestação pública no SNS - manteve-se, embora fosse frequente o acesso a consultas em consultórios privados e o pagamento do próprio bolso ("out-of-pocket").

Todavia, nos últimos 20 anos tem sido notória a emergência de fortes grupos privados de saúde, alguns dos quais, estrangeiros, que em grande medida assentam a sua faturação em seguros privados (planos de saúde) subscritos por empresas e por famílias, na ADSE (plano público de saúde limitado aos trabalhadores em funçôes públicas) e outros subsistemas de saúde e em prestaçóes do sistema SIGIC (Sistema Integrado de Gestão de Inscritos para Cirurgia), que visa combater as listas de espera em cirurgias.

Assim, podemos constatar que o sistema de saúde português tem um carácter misto, com uma forte presença do sistema público (SNS), mas com mais de $20 \%$ da população a recorrer, em grande medida, ao sistema privado e social. Assim, o sistema de saúde português é caracterizado por três sistemas coexistentes e sobrepostos: o SNS universal; regimes especiais de seguro de saúde para determinadas profissóes ou setores (por exemplo, funcionários públicos, empregados em bancos e companhias de seguros), denominados subsistemas de saúde; e seguro de saúde voluntário privado.

Assim, em Portugal existe um sistema de saúde misto, com diferentes modelos de pagamento, isto é, um modelo baseado no Serviço Nacional de Saúde (SNS) financiado através do Orçamento do Estado; um modelo baseado no seguro social financiado por fundos de saúde de matriz profissional; um modelo baseado no seguro 
voluntário financiado individualmente e um modelo baseado em pagamentos diretos ${ }^{3}$.

Em Portugal, o sistema de saúde inclui prestadores públicos, privados e sociais. O SNS tem especial relevância porque tem um carácter universal. Como tal, melhorar a eficiência e a eficácia do SNS tem estado na base de um conjunto vasto de medidas e reformas que foram implementadas nos últimos anos.

O Ministério da Saúde é responsável pela alocação de recursos para o SNS. O orçamento global para o SNS é distribuído pelas várias instituiçóes com base em despesas históricas. Mais recentemente, métodos de pagamento foram introduzidos para cobrir os custos gerais de algumas patologias. A área da oncologia tem um modelo de atenção próprio, constituído por três centros altamente especializados (os Institutos Portugueses de Oncologia Francisco Gentil (IPO)), localizados nas cidades de Lisboa, Porto e Coimbra, e que cobrem toda a área geográfica de Portugal, complementados pela prestação de cuidados em hospitais gerais.

A prestação de Cuidados Continuados e de Cuidados Paliativos está também organizada em redes específicas, articuladas entre os Ministérios da Saúde e da Segurança Social, e com um impulso muito importante do setor social da saúde, em particular das IPSS - Instituiçóes Particulares de Solidariedade Social e das Misericórdias.

\section{b) A participação dos Doentes nas Decisóes de Saúde}

No que respeita à democracia sanitária, e ao contrário do que acontece noutros países da Europa, em Portugal os doentes não têm, genericamente, assento nos conselhos de administração ou de direção dos hospitais, que são formados, em grande medida, por profissionais de saúde e da área da gestão. A democracia sanitária e a flexibilização da relação-médico paciente ficam, assim, prejudicadas, aspeto só menorizado pelo facto de os doentes constituírem associaçóes privadas que promovem o diálogo com as entidades de saúde em nome coletivo.

O associativismo e a constituição de grupos informais de representação e participação na saúde encontram amplo respaldo no nosso

3 Sobre o sistema de saúde português vide SIMÓES, Jorge, CORREIA DE CAMPO, António, O Percurso da Saúde: Portugal na Europa, Almedina, 2011. 
sistema jurídico, e a Lei de Bases da Saúde, de acordo com a nossa Constituição, prevê expressamente o direito dos cidadãos a intervir nos processos de tomada de decisão em saúde e na gestão participada das instituições do SNS.

Várias organizaçóes e entidades internacionais, entres elas o European Patients' Forum (EPF), a Organização Mundial de Saúde (OMS) e a Organização para a Cooperação e Desenvolvimento Económico (OCDE) defendem a participação pública no âmbito da saúde.

A reforma realizada em França, designadamente, a partir de 2002, operou com eficácia uma resposta a estes desafios, colocando a primazia na dimensão da démocratie sanitaire, sendo os poderes coletivos dos doentes uma das dimensóes mais relevantes. Com efeito, o artigo L1114-1 do Código de Saúde Pública francês passou a prever, designadamente, que as associaçôes, regularmente constituídas, com uma atividade no domínio da qualidade da saúde e assistência ao paciente, possam ser aprovadas por autoridade administrativa competente a nível regional ou nacional para representar os utentes, na direção ou administração das unidades de saúde, ou autoridades de saúde pública.

Os representantes dos utentes têm direito a formação para facilitar o exercício deste mandato. Repare-se que náo se trata de um papel meramente consultivo, mas, efetivamente, de participar ativamente e em pé de igualdade com gestores, diretores e administradores na definição do funcionamento. É a forma de assegurar uma participação efetiva dos doentes na gestão da saúde, através dos seus participantes.

Em Portugal não se tem verificado uma preocupação específica e concretizada no sistema jurídico com esta questão, e até há pouco não era claro qualquer papel importante dos doentes na gestão e administração de serviços de saúde, ou no quadro institucional de formação dos profissionais de saúde.

A Carta para a Participação Pública em Saúde, aprovada pela Lei n. ${ }^{\circ}$ 108/2019, de 9 de setembro de 2019, pretendeu alterar este estado de coisas. Nasceu com o objetivo de fomentar a participação por parte das pessoas, com ou sem doença e seus representantes, nas decisóes que afetam a saúde da população, e incentivar a tomada de decisão em saúde assente numa ampla participação pública, consolidando a participação pública a nível político e dos diferentes órgãos e entidades do Estado, em Portugal, através do aprofundamento dos processos de 
participação já existentes e da criação de novos espaços e mecanismos participativos $^{4}$.

Ora, o que agora se impóe verificar e assentar são, precisamente, os mecanismos existentes de participação dos doentes e dos seus representantes, e qual o seu impacto efetivo nas políticas da saúde. De acordo com a Carta, a participação pública das pessoas com ou sem doença e seus representantes abrange, nomeadamente, as seguintes áreas: plano Nacional de Saúde e programas de saúde; gestão do SNS, incluindo recursos humanos, materiais e financeiros, e organização da prestação dos cuidados de saúde, através dos agrupamento de centros de saúde e dos hospitais; orçamento do Estado para a saúde; avaliaçáo de tecnologias de saúde; avaliação da qualidade em saúde; normas e orientaçóes; ética e investigação em saúde; direitos das pessoas com ou sem doença e seus representantes. Há vasta evidência internacional sobre a importância da operacionalidade democrática e da representação na gestão da saúde que é necessário comparar e ajustar no nosso sistema.

Se no conceito de democracia sanitária emerge como estrutural uma dimensão individual, traduzível no apoio à decisão e no empoderamento do doente, designadamente, pelo verdadeiro respeito pelo direito à informaçáo e ao esclarecimento e pelo direito de acesso e controlo da sua informação de saúde, é de realçar que deve ser reforçada a dimensão coletiva, no sentido da efetivação dos direitos dos

4 A Carta para a Participação Pública em Saúde contribui para: promover e defender os direitos das pessoas com ou sem doença, em especial no que respeita à proteçâo da saúde, da informação e da participação; informar as entidades públicas sobre as prioridades, necessidades e preocupaçóes das pessoas com ou sem doença e seus representantes; tornar as políticas de saúde mais eficazes e, consequentemente, obter melhores resultados em saúde; promover a transparência das decisóes e a prestação de contas por parte de quem decide; aproximar o Estado e a sociedade civil, aprofundando o diálogo e a interação regular entre ambos; legitimar as decisóes sobre a avaliação custo -efetividade e os dilemas éticos colocados pelas inovaçóes tecnológicas.

A participação pública em saúde deve assentar nos seguintes princípios: reconhecimento da participação pública como direito das pessoas com ou sem doença e seus representantes; reconhecimento das pessoas com ou sem doença e seus representantes como parceiros nos processos de tomada de decisão; reconhecimento da importância do conhecimento e da experiência específicos da pessoa com ou sem doença; autonomia e independência das pessoas com ou sem doença e seus representantes nos processos; transparência e divulgação pública dos processos participativos; criaçáo das condiçôes necessárias à participação; complementaridade e integração entre instituiçôes e mecanismos da democracia representativa e da democracia participativa. 
doentes, através da criação e legitimação das associações de doentes, e das ONG's, em geral, conduzindo consequentemente a um reforço da sociedade civil.

\section{c) Soluçóes e oclusóes do sistema, em contexto de pandemia}

Nestas diferentes dimensōes - 1) a qualidade da prestação de cuidados de saúde e 2) a promoção da participação dos doentes nas políticas e decisôes de saúde - o sistema de saúde português resultou gravemente empobrecido no contexto da pandemia.

O SNS aumentou muito significativamente a sua capacidade de prestar cuidados de saúde, aumentando e continuando a aumentar, em centenas, as camas, os profissionais de saúde, os meios complementares de diagnóstico e terapêutica e os dispositivos médicos, num crescendo inigualável. A resposta oferecida pelo SNS revelou-se bastante robusta - em celeridade, adequação, qualidade e quantidade. Parece-nos que mais robusta do que seria uma resposta privada no mesmo contexto, dadas as exigências de rápida decisão e coordenação que se exigiu nos picos pandémicos. Porém, as fragilidades do sistema acentuaram-se até porque a disponibilidade de recursos quer falemos de meios humanos quer de equipamentos não é elástica e a procura, essa, por sua vez, não para de aumentar.

\section{Testagem}

No que respeita à testagem, o Ministério da Saúde organizou e monitorizou um sistema de testes, gratuitos para o utilizador, dentro do quadro de indicaçôes da Direção Geral de Saúde. Assim, todas as pessoas que desenvolvam quadro clínico sugestivo de infeção respiratória aguda com pelo menos um dos seguintes sintomas: tosse de novo ou agravamento da tosse habitual ou associada a cefaleias ou mialgias, ou febre: temperatura $\geq 38.0^{\circ} \mathrm{C}$ sem outra causa atribuível, ou dificuldade respiratória/dispneia, sem outra causa atribuível perda total ou parcial do olfato (anosmia), enfraquecimento do paladar (ageusia) e perturbação ou diminuição do paladar (disgeusia) de início súbito, são considerados suspeitos de COVID-19, e têm indicação para teste (gratuito), nos centros de referência. Grande parte desta monitorização está a cargo da Linha Saúde 24, através da qual todos os cidadãos podem 
obter informação sobre o encaminhamento adequado da sua situação. Contudo, o teste laboratorial para SARS-CoV-2 poderá ser pedido (só assim será gratuito) pelo médico das equipas das unidades de saúde familiares (USF) / unidade de cuidados de saúde personalizados (UCSP) para os doentes com indicação para vigilância clínica e isolamento no domicílio, de forma remota através da plataforma Exames Sem Papel, pelo médico das equipas das ADR-C (áreas dedicadas a doentes respiratórios nos cuidados de saúde primários) ou ADR-SU (áreas dedicadas a doentes respiratórios nas unidades hospitalares) ou por qualquer médico que durante a avaliação clínica considere a suspeita de COVID-19, excecionalmente e de forma automática pelos profissionais de saúde do SNS24 que façam triagem clínica, através da geração da requisição de testes, mediante aplicação de algoritmo aprovado pela Direção-Geral da Saúde.

O teste de referência para o diagnóstico da COVID-19 é o Teste Molecular de Amplificação de Ácidos Nucleicos (TAAN). Não obstante, em situação de surto, são realizados testes rápidos de antigénio, para reduzir o tempo de obtenção de resultados e implementar as medidas necessárias. Os testes utilizados em Portugal são os recomendados pelas autoridades de saúde internacionais, quer pelo Centro Europeu de Controlo de Doenças (ECDC), quer pela Organização Mundial de Saúde (OMS).

Os doentes sem sintomas de COVID-19 não têm, em princípio, indicação expressa para fazer o teste gratuito, de acordo com o procedimento definido pela Direção Geral de Saúde. Poderão fazê-lo por sua iniciativa, ou no âmbito das instituiçóes onde prestem habitualmente a sua atividade profissional, quando estas promovam o rastreio. No âmbito do setor privado de saúde existe ampla oferta de testagem, com diferentes procedimentos e preços.

\section{Tratamento}

O tratamento da COVID-19 é gratuito, no âmbito do SNS. O internamento, os exames complementares de diagnóstico e a terapêutica em contexto hospitalar é universal e gratuita. Quando não haja necessidade de internamento, os medicamentos adquiridos em farmácia comunitária respeitam os regimes geral e especiais de comparticipação do Estado no preço dos medicamentos. 
Considerando a escassez de meios do SNS foi contratualizado com unidades hospitalares privadas o tratamento de alguns doentes que, numa situação normal, seriam acompanhados no âmbito do SNS.

\section{Vacinação}

No que concerne à vacinação, toda a população portuguesa poderá ser vacinada, de forma totalmente gratuita, desde que seja elegível de acordo com as indicaçóes clínicas aprovadas para cada vacina na Uniáo Europeia. Contudo, foram definidos grupos prioritários, por estarem mais vulneráveis à COVID-19.

Segundo o plano de vacinação, que pode sofrer alteraçóes em função da evolução do conhecimento científico e das indicações e contraindicaçôes que venham a ser aprovadas pela Agência Europeia de Medicamentos, a estratégia de vacinação será a seguinte: ${ }^{5}$

- Fase 1, a partir de dezembro de 2020:

- Profissionais de saúde envolvidos na prestaçáo de cuidados a doentes

- Profissionais das forças armadas, forças de segurança e serviços críticos

- Profissionais e residentes em Estruturas Residenciais para Pessoas Idosas (ERPI) e instituiçóes similares

- Profissionais e utentes da Rede Nacional de Cuidados Continuados Integrados (RNCCI).

A partir de fevereiro de 2021:

- Pessoas com 80 ou mais anos de idade. ${ }^{6}$

- Pessoas de idade $\geq 50$ anos, com pelo menos uma das seguintes patologias:

- Insuficiência cardíaca

- Doença coronária

5 Cf. https://covid19.min-saude.pt/vacinacao/

6 Foi importante a participação empenhada de um grupo de cidadãos, em que se inclui o primeiro signatário deste texto, no sentido de defender o alargamento da prioridade aos cidadãos com mais de 80 anos. Cf. Carta Aberta sobre os critérios para vacinação prioritária no Plano de Vacinação contra a covid-19, in Público, 26 de janeiro de 2021: https:/www.publico.pt/2021/01/26/sociedade/opiniao/carta-aberta-criterios-vacinacao-prioritaria-plano-vacinacao-covid19-1947843 
- Insuficiência renal (Taxa de Filtração Glomerular $<60 \mathrm{ml} / \mathrm{min}$ )

- (DPOC) ou doença respiratória crónica sob suporte ventilatório e/ou oxigenoterapia de longa duração

- Fase 2, a partir de abril de 2021:

- Pessoas de idade $\geq 65$ anos (que náo tenham sido vacinadas previamente)

- Pessoas entre os 50 e os 64 anos de idade, inclusive, com pelo menos uma das seguintes patologias:

- Diabetes

- Neoplasia maligna ativa

- Doença renal crónica (Taxa de Filtração Glomerular > 60ml/ $\min )$

- Insuficiência hepática

- Hipertensão arterial

- Obesidade

- Outras patologias com menor prevalência que poderão ser definidas posteriormente, em funçáo do conhecimento científico

- Fase 3, em data a determinar após a conclusão da segunda fase:

- Toda a restante população elegível, que poderá ser igualmente priorizada.

\section{d) Articulação entre o Sistema de saúde e o Sistema de Segurrança social}

A crise pandémica acarreta graves consequências socioeconómicas, diminuindo a produtividade e os rendimentos das famílias, e aumentando o desemprego e as despesas quotidianas. Portugal criou um conjunto de apoios «ad hoc» para minimizar estes efeitos.

\section{Para os empregadores}

Através da Segurança Social, para as entidades empregadoras foram criadas as seguintes medidas de apoio ao emprego:

- Layoff Simplificado (Medida Extraordinária de Apoio à Manutençáo dos Contratos de Trabalho)

- Apoio à Retoma (Apoio Extraordinário à Retoma Progressiva de Atividade) 
No primeiro trimestre de 2021, as entidades empregadoras beneficiam da suspensão de execuções por dívidas à segurança social e da suspensão dos planos prestacionais em curso. Beneficiam também do diferimento de obrigaçóes contributivas relativas aos meses de novembro e dezembro de 2020 .

\section{Para os traballhadores por conta de outrem}

Através da Segurança Social, os trabalhadores por conta de outrem, incluindo membros de órgãos estatutários e trabalhadores do serviço doméstico, mantém o acesso às medidas extraordinárias de proteção social:

- Subsídio por doença por Isolamento Profilático

- Subsídio por doença por Covid-19

- Subsídio por doença por Covid-19 de trabalhadores do Sector da Saúde

- Assistência a filho ou neto por Isolamento Profilático

A medida de Assistência a Filho ou Neto por Isolamento Profilático é aplicável aos trabalhadores que não possam exercer a sua atividade por motivos de assistência a filhos ou outros dependentes a cargo, menores de 12 anos, ou com deficiência ou doença crónica independentemente da idade, em situação de isolamento profilático, certificado pelo Delegado de Saúde ou de doença por COVID-19. Tem direito a subsídio por assistência a filho, de valor correspondente a $100 \%$ da remuneração de referência líquida, tendo como limite mínimo $65 \%$ da remuneração ilíquida. Este valor está em vigor desde 01 de abril de 2020.

Caso se trate de assistência a neto, o valor do subsídio corresponde a $65 \%$ da remuneração de referência. $\mathrm{O}$ valor da remuneração de referência líquida obtém-se pela dedução, ao valor ilíquido da remuneração de referência, da taxa contributiva aplicável ao beneficiário e da taxa de retenção do imposto sobre rendimento das pessoas singulares (IRS).

Foi também efetuado um trabalho de comunicação em larga escala, no sentido de informar os trabalhadores acerca dos seus direitos sociais, designadamente através de cartazes, como este: 


\section{COVID-19 | Se faltar ao trabalho, como proceder?}

Se for obrigado a ficar em casa devido ao novo Coronavírus poderá necessitar de um documento que comprove a sua situação clínica, justifique as suas faltas e possibilite a sua remuneração.

Saiba como deve proceder e quem o pode ajudar.

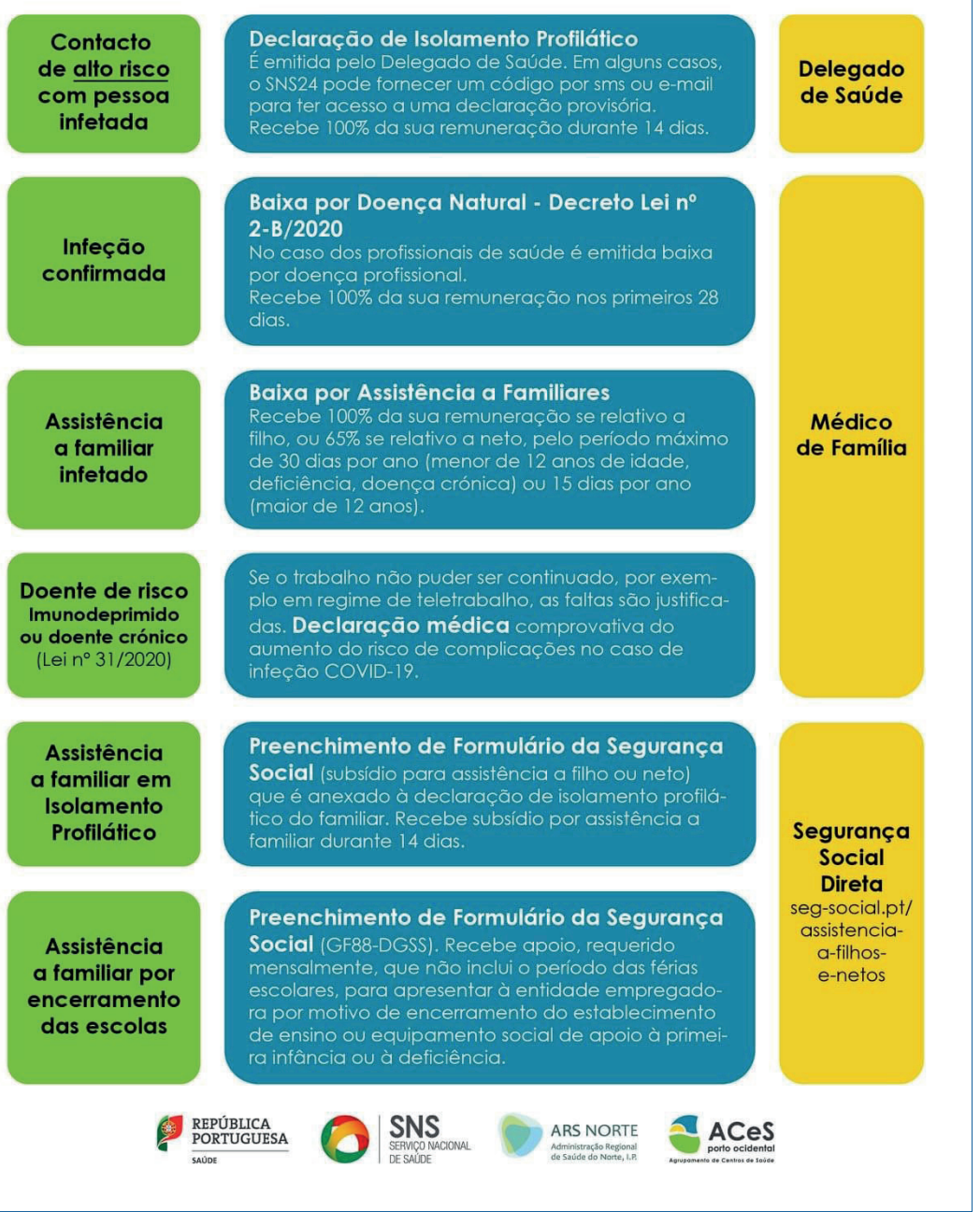

Fonte: ARS Norte

\section{Para os traballhadores independentes}

Providenciado pela Segurança Social, e destinado aos trabalhadores independentes, incluindo empresários em nome individual, sujeitos à suspensão de atividades ou encerramento de instalaçóes e 
estabelecimentos por determinação legislativa ou administrativa de fonte governamental, no estado de emergência, foram criados diferentes apoios, designadamente, as seguintes medidas de apoio ao emprego:

- Apoio Extraordinário à redução da atividade económica de trabalhador independente

- Medida Extraordinária de Incentivo à Atividade Profissional

- Apoio à Desproteção Social

\section{Para os Equipamentos Sociais e de Saúde}

Através do IEFP - Instituto do Emprego e da Formação Profissional - foi criado o Programa de Apoio ao Reforço de Emergência de Equipamentos Sociais e de Saúde, com o Reforço de Emergência de Equipamentos Sociais e de Saúde (MAREES), uma medida temporária e excecional, que consiste no apoio à realização de trabalho socialmente necessário, para assegurar a capacidade de resposta das instituiçóes públicas e do setor solidário com atividade na área social e da saúde, durante a pandemia da doença COVID-19.

Esta medida teve por objetivo contribuir para assegurar a capacidade de resposta das instituiçóes públicas e do setor solidário com atividade na área social e da saúde, nomeadamente serviços de saúde, hospitais, lares ou estruturas residenciais para pessoas idosas e pessoas com deficiência e incapacidade; promover a empregabilidade de pessoas em situação de desemprego, preservando e melhorando as suas competências socioprofissionais, através da manutenção do contacto com o mercado de trabalho; e possibilitar uma melhoria dos rendimentos dos desempregados ou dos trabalhadores com contrato de trabalho suspenso, horário reduzido ou com contrato de trabalho a tempo parcial.

Tem como destinatários os desempregados beneficiários de subsídio de desemprego, ou sem subsídio de desemprego, trabalhadores com contrato de trabalho suspenso ou horário de trabalho reduzido, trabalhadores com contratos de trabalho a tempo parcial, e estudantes, designadamente do ensino superior, bem como formandos, preferencialmente de áreas relacionadas com os projetos, com idade náo inferior a 18 anos. 


\section{e) Efeitos nos Direitos dos Doentes}

No contexto da pandemia o Governo emitiu Diretrizes, através do Ministério da Saúde, a suspender atividade programada e não prioritária. O último desses diplomas, o Despacho n. ${ }^{\circ}$ 574-A/2021, atualmente em vigor, determina que estabelecimentos hospitalares do Serviço Nacional de Saúde (SNS) passem os seus Planos de Contingência para o nível máximo e suspendam a atividade assistencial programada náo urgente que possa reverter em reforço de cuidados ao doente crítico.

A referida medida é justificada com o surgimento e a propagação do vírus SARS-CoV-2 em Portugal o que determinou a necessidade de assegurar a prevenção, contenção, mitigação e tratamento da COVID-19, através da adoção de um conjunto de medidas excecionais e temporárias de resposta à pandemia. Em Janeiro de 2021, data da publicação do referido diploma, Portugal registava uma taxa de notificação acumulada a 14 dias acima dos 900 casos por 100000 habitantes e um número médio de casos secundários resultantes de um caso infetado, medido em função do tempo, $\mathrm{R}(\mathrm{t})$, superior a 1 .

Estes fatores colocam o sistema de saúde, e em particular o Serviço Nacional de Saúde (SNS), sob elevada pressão, em especial no internamento hospitalar (internamento em enfermaria e internamento em cuidados intensivos ambos com taxas de ocupaçáo, em janeiro, que se situam entre $85 \%$ e $96 \%$ ). Em janeiro de 2021 foi atingido o número máximo de internamentos por COVID-19 nas instituições do SNS, desde o início da pandemia. Com o confinamento rigoroso de fevereiro e março, a situação pandémica ficou controlada e a saúde pública foi salvaguardada.

Considerada a atual situação epidemiológica, a ocupação de camas de enfermaria e de cuidados intensivos e a necessidade de garantir resposta a uma procura que foi exponencial (em janeiro e fevereiro de 2021), e com o intuito de assegurar a mobilização de todos os profissionais de saúde habilitados a uma resposta alinhada com a procura de cuidados observada foram, então, publicadas as guidelines de alocação de recursos.

De acordo com estas diretrizes os estabelecimentos hospitalares do Serviço Nacional de Saúde (SNS) devem assegurar a prontidão da resposta à COVID-19 e o melhor equilíbrio possível das várias respostas 
assistenciais, em especial ao nível da Medicina Intensiva. Para concretização desta priorização os estabelecimentos de saúde:

a) passaram os seus Planos de Contingência para o nivel máximo e procederam à sua revisão e expansão, de forma a maximizar a resposta da capacidade hospitalar à situação epidemiológica local, regional e nacional, em articulação com a Comissão de Acompanhamento da Resposta Nacional em Medicina Intensiva (CARNMI) e as Administraçóes Regionais de Saúde respetivas;

b) suspenderam a atividade assistencial programada não urgente que possa reverter em reforço de cuidados ao doente crítico, desde que tal suspensão, pela sua natureza ou prioridade clinica, não implique risco de vida para os utentes, limitação grave do seu prognóstico e ou limitaçâo de acesso a tratamentos periódicos ou de vigilância, designadamente no âmbito do acompanhamento da gravidez, exacerbaçâo das doenças crónicas ou outros;

c) procederam ao diferimento de atividade cirúrgica programada de prioridade normal ou prioritária;

d) promoveram a alocação de meios humanos para a Medicina Intensiva, de modo a maximizar a capacidade de resposta nesta área, em conformidade com a suspensão e diferimento de atividade assistencial efetuada, mediante proposta da CARNMI e sempre em articulação com a direção clínica de cada unidade.

Considerando o exposto em termos de alocação de recursos o Governo português deu total prioridade ao combate à pandemia relegando para segundo plano todas as outras patologias que careçam de acompanhamento hospitalar. Este facto tem-se traduzido num elevado aumento da mortalidade em Portugal derivado de outras patologias que não as decorrentes de infeção pelo vírus SARS-CoV-2.

No balanço feito pelo Instituto Nacional de Estatística, entre 2 de março e 27 de dezembro de 2020, foram registados, em Portugal, 99.356 óbitos o que representa mais 12.852 quando comparado com a média dos últimos cinco anos. Destes apenas 52\% - ou seja 6.677 foram óbitos por covid-19.

$\mathrm{O}$ acompanhamento às restantes patologias não deixou de existir. O Ministério da Saúde português teve, inclusive, de esclarecer que o Despacho enviado aos hospitais náo manda suspender a cirurgia urgente ou muito prioritária e não se aplica a hospitais como o Institu- 
to Português de Oncologia (dedicado, em exclusivo, ao tratamento de doentes oncológicos). O Ministério da Saúde (MS) assegura que "o diferimento de atividade cirúrgica será sempre feito mediante avaliação clínica e garantia de que não ocorre limitação do prognóstico do utente". Adianta ainda que a cirurgia oncológica prioritária deve ocorrer até 45 dias após a indicação cirúrgica, sublinhando que o despacho vigora até 31 de janeiro. Segundo o MS, "o despacho não se aplica a hospitais como os IPO que, de acordo com o funcionamento em rede, estâo disponíveis para receber os doentes que requeiram cirurgia prioritária durante o período de aplicação do despacho".

Acresce que esta situação pandémica teve especial impacto em alguns direitos consolidados dos doentes, designadamente, nos tempos máximos de resposta garantidos, no livre acesso e circulação no SNS e no direito de visita.

\section{Tempos Máximos de Resposta Garantidos}

A Carta dos Direitos de Acesso aos Cuidados de Saúde, pelos Utentes do Serviço Nacional de Saúde (SNS), determina que o utente do SNS tem direito não só à prestaçáo de cuidados em tempo considerado clinicamente aceitável para a sua condição de saúde, como também o cumprimento dos tempos máximos de resposta garantidos (TMRG) definidos anualmente por portaria do Ministério da Saúde para todo o tipo de prestação de cuidados sem carácter de urgência e ainda a reclamar para a Entidade Reguladora da Saúde caso os TMRG náo sejam cumpridos.

Em Portugal, os tempos máximos de resposta garantidos encontram-se definidos por via legal. Após a Lei n. ${ }^{\circ}$ 15/2014, de 21 de março ter consolidado a legislação em matéria de direitos e deveres do utente dos serviços de saúde, a Portaria n. ${ }^{\circ}$ 153/2017, de 04 de maio, veio definir os Tempos Máximos de Resposta Garantidos no SNS, em função da prioridade clínica. Contudo, de acordo com a informação veiculada pelo Governo, durante a primeira vaga da pandemia, em maio de 2020, houve uma quebra muito significativa na atividade do Serviço Nacional de Saúde devido à pandemia COVID-19, que se traduziu, ao nível dos cuidados de saúde primários, numa queda de consultas de 3.9\% (menos 300.000 consultas), e nas consultas hospitalares de 5.7\% (menos 180.000 consultas). 
No que diz respeito às cirurgias programadas para o SNS, no mesmo período, registou-se uma diminuição de 5.3\% (menos 9.000) e a quebra geral nos serviços de urgência foi de $11.5 \%$.

Sabemos, também, que os exames complementares de diagnóstico tiveram em algumas áreas (como a gastroenterologia) uma descida de $25 \%$. A cirurgia oncológica foi reduzida em 15\% e a procura dos serviços de Urgência desceu, em alguns dos dias registados, 50\%. A SPO - Sociedade Portuguesa de Oncologia - estima uma redução de 80\% nos diagnósticos de cancro (ao Jornal Expresso, 11-05-2020).

A situação degradou-se acentuadamente a partir de janeiro de 2021 .

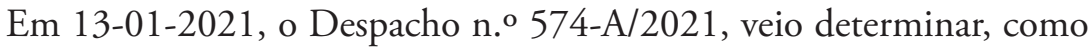
já referimos, que estabelecimentos hospitalares do Serviço Nacional de Saúde (SNS) passem os seus Planos de Contingência para o nível máximo e suspendam a atividade assistencial programada não urgente. Com esta decisão, e de acordo com o objetivo de maximização da capacidade instalada, foi necessário suspender a atividade assistencial programada (que não coloque o utente em risco de vida ou de grave prejuizo, atendendo à sua prioridade clinica).

No final de Dezembro estavam inscritos para uma cirurgia oncológica mais de 5000 doentes. O Ministério da Saúde tem sido interpelado para e anuncia planos para redução das listas de espera, recorrendo ao setor privado e social, mas ainda é cedo para avaliar a realidade prática e o eventual sucesso desses planos. ${ }^{7}$

O que é seguro - de acordo com as atualizações permanentes da Escola Nacional de Saúde Pública - , entre fevereiro de 2020 e fevereiro de 2021, a mortalidade em Portugal, excluídos os números referentes à infeção por SARS-COV2, foi a mais alta dos últimos dez anos.

\section{Livre Acesso e Circulação no SNS}

Em Portugal, o sistema de Livre Acesso e Circulação de Utentes no SNS (LAC), aprovado pelo Despacho n. $5911-\mathrm{B} / 2016$, de 3 de maio, permite ao utente, em conjunto com o médico de família responsável pela referenciação, optar por qualquer uma das unidades hospitalares do SNS onde exista a consulta de especialidade de que necessita.

7 https:/www.publico.pt/2021/02/10/sociedade/noticia/ministerio-saude-prepara-plano-recuperar-cirurgia-oncologica-ficou-1950159 
A referenciação é efetuada de acordo com o interesse do utente, segundo critérios de proximidade geográfica e considerando os tempos médios de resposta nas instituiçóes.

O nível máximo de contingência colocou em causa o livre acesso e circulação de doentes. Atualmente, a oferta de cuidados de saúde recebe atualizaçóes quase diárias, em função da necessidade de abertura de novas enfermarias e hospitais, que procuram amparar uma necessidade desmesurada de cuidados de saúde. Ao mesmo passo, muitos profissionais de saúde com formação específica foram alocados a outras especialidades médicas, designadamente, em plataformas de apoio aos cuidados intensivos e à pneumologia. Esta realidade alterou drasticamente a realidade das redes basilares de referenciação.

\section{Direito de acompanhamento e de visita}

De acordo com a lei portuguesa dos Direitos e deveres do utente dos serviços de saúde (Capítulo III da Lei n. ${ }^{\circ}$ 15/2014, de 21 de março), a todos é reconhecido e garantido o direito de acompanhamento por uma pessoa por si indicada, devendo ser prestada essa informação na admissão pelo serviço. Às mulheres grávidas internadas em estabelecimento de saúde é também reconhecido o direito de acompanhamento, durante todas as fases do trabalho de parto, por qualquer pessoa por si escolhida.

É ainda reconhecido o direito de acompanhamento familiar a crianças internadas em estabelecimento de saúde, bem como a pessoas com deficiência, a pessoas em situação de dependência e a pessoas com doença incurável em estado avançado e em estado final de vida.

Nos casos em que a situação clínica não permita ao utente escolher livremente o acompanhante, os serviços devem promover o direito ao acompanhamento, podendo para esse efeito solicitar a demonstração do parentesco ou da relação com o utente invocados pelo acompanhante.

A Carta dos Direitos do Doente Internado, da Direção Geral de Saúde, no seu ponto 13 refere que o doente internado tem direito à visita dos seus familiares e amigos quando o desejar e os horários o permitam, sempre que não exista contra-indicação. As instituiçóes e os profissionais devem facilitar e mesmo incentivar o apoio afectivo que podem dar "entes significativos" para o doente. As situaçóes familiares mais complicadas onde existem conflitos entre os diferentes familiares e 
/ ou amigos têm que ser ponderadas discreta e subtilmente pelos profissionais. Os doentes que não têm visitas e se sentem isolados devem ter um maior apoio quer do pessoal de saúde, quer do pessoal voluntário devidamente preparado e enquadrado. $\mathrm{O}$ doente internado que se mostre incapaz de compreender ou de se fazer compreender tem direito ao acompanhamento da pessoa que habitualmente lhe presta cuidados e para a qual deve haver condiçôes mínimas.

Quando a pessoa internada náo esteja acompanhada, a administração do estabelecimento de saúde deve diligenciar para que lhe seja prestado o atendimento personalizado necessário e adequado à situação.

Apenas não é permitido acompanhar ou assistir a intervençóes cirúrgicas e a outros exames ou tratamentos que, pela sua natureza, possam ver a sua eficácia e correçáo prejudicadas pela presença do acompanhante, exceto se para tal for dada autorização expressa pelo clínico responsável. Em geral, o acompanhamento não pode comprometer as condiçôes e requisitos técnicos a que deve obedecer a prestação de cuidados médicos.

As unidades de saúde, públicas e privadas, definem os seus regulamentos de visitas em função das dinâmicas dos serviços, sendo certo que, por via de regra, os doentes podem sempre receber visitas, cumprindo as exigências genericamente definidas naqueles regulamentos.

Em certas situaçóes específicas, como as situaçóes de fim de vida, é a própria lei a afirmar perentoriamente um princípio transversal e de valor reforçado ao direito de visita.

Contudo, também os acompanhamentos e as visitas a doentes sofreram importantes revezes com a situação pandémica. Se algumas destas limitaçóes tiveram fundamento direto e objetivo na adequação das condições da prestação de cuidados, e efetuaram-se em estrito respeito pelas recomendaçóes da Direção Geral de Saúde, outras limitaçóes deveram-se a falhas na organização dos serviços e arbitrariedade das opçôes, que tiveram como consequência situaçôes de profunda solidão e isolamento de pessoas especialmente vulneráveis.

Também no que concerne às visitas aos utentes, a pandemia impôs um conjunto de medidas de carácter extraordinário nas Estruturas Residenciais para Idosos (ERPI), Unidades de Cuidados Continuados Integrados (UCCI) da Rede Nacional de Cuidados Continuados Integrados (RNCCI) e Estabelecimentos de Apoio Social para Crianças, Jovens, Pessoas Idosas ou Pessoas com Deficiência. 
Num primeiro momento, as visitas foram absolutamente proibidas na maior parte destes espaços, acreditando-se que a medida seria fundamental para conter as redes de contágio. A partir de maio de 2020, contudo, a Direção Geral de Saúde determinou a cessação da suspensão, definindo limites quer quanto à quantidade e periodicidade das visitas, quer quanto às condiçôes ambientais em que as mesmas devem decorrer, assim proporcionando um retorno parcial aos contactos familiares e sociais fundamentais.

Com a nova e fortíssima vaga pandémica de janeiro de 2021, as limitaçôes ao direito de visita voltaram, embora com menos rigor, ${ }^{8} \mathrm{o}$ que se compreende pelo facto de concomitantemente ter sido feita a campanha de vacinação de todos os utentes e funcionários desses serviços residenciais.

\section{Conclusáo}

Terminamos como começámos, o estado de emergência decorrente da pandemia, em caso algum pode afetar os direitos à vida, à integridade pessoal, à identidade pessoal, à capacidade civil e à cidadania, à náo retroatividade da lei criminal, às garantias de defesa dos arguidos e à liberdade de consciência e de religiáo. Contudo, permite a implementação de certas medidas restritivas. Na saúde, fruto da escassez dos recursos, perante uma oferta inelástica, assistimos ao implementar de guidelines que, necessariamente, acarretam, restriçóes para os doentes quer no acesso aos cuidados de saúde quer no exercício dos seus direitos enquanto doentes. Certo é que essas "restriçôes" não podem colocar em causa a sua vida ou a sua saúde.

8 Por exemplo, as visitas a lares de idosos e as atividades nos centros de dia foram permitidas no período do estado de emergência que começou às 00:00 de dia 15 de janeiro, para tentar conter o avanço da pandemia de covid-19. 